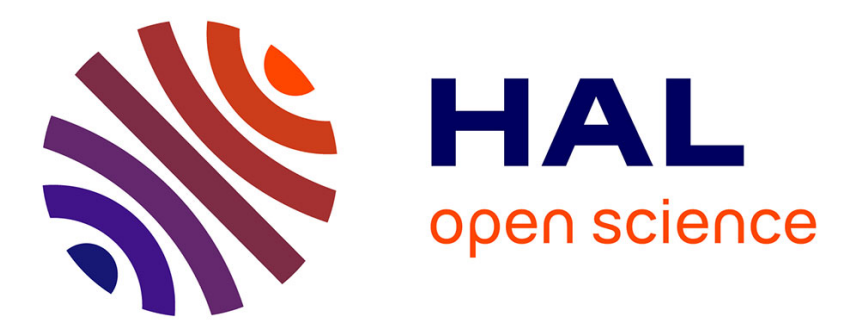

\title{
PLM Process and Information Mapping for Mass Customization Based on Additive Manufacturing
}

Eduardo De Senzi Zancul, Gabriel Delage E Silva, Luiz S. Durão, Alexandre M. Rocha

\section{- To cite this version:}

Eduardo De Senzi Zancul, Gabriel Delage E Silva, Luiz S. Durão, Alexandre M. Rocha. PLM Process and Information Mapping for Mass Customization Based on Additive Manufacturing. 12th IFIP International Conference on Product Lifecycle Management (PLM), Oct 2015, Doha, Qatar. pp.846855, 10.1007/978-3-319-33111-9_77 . hal-01377515

\section{HAL Id: hal-01377515 https://hal.inria.fr/hal-01377515}

Submitted on 7 Oct 2016

HAL is a multi-disciplinary open access archive for the deposit and dissemination of scientific research documents, whether they are published or not. The documents may come from teaching and research institutions in France or abroad, or from public or private research centers.
L'archive ouverte pluridisciplinaire HAL, est destinée au dépôt et à la diffusion de documents scientifiques de niveau recherche, publiés ou non, émanant des établissements d'enseignement et de recherche français ou étrangers, des laboratoires publics ou privés.

\section{(c)(1)}

Distributed under a Creative Commons Attribution| 4.0 International License 


\title{
PLM process and information mapping for mass customization based on additive manufacturing
}

\author{
Eduardo de Senzi Zancul ${ }^{1 *}$, Gabriel Delage e Silva ${ }^{1}$, Luiz Fernando C. S. Durão ${ }^{1}$, \\ Alexandre M. Rocha ${ }^{1 .}$ \\ ${ }^{1}$ University of São Paulo, Brazil \\ ezancul@usp.br \\ gabriel.delage.silva@usp.br \\ luiz.durao@usp.br \\ arocha@usp.br \\ * To whom correspondence should be addressed
}

\begin{abstract}
Mass customization (MC) aims to support product individualization while maintaining scale advantages. There are different options to allow individual client influence throughout the product production process. Most efforts to bring the customer closer to manufacturing of their customized product are concentrated in the assembly stage, given the complexity to consider individual needs since design. Emerging information management and flexible manufacturing technologies can support advances in current customization approaches and levels. In this paper, Product Lifecycle Management (PLM) and Additive Manufacturing (AM) solutions and technologies are applied to build a tailored customization scenario for the design and production of an assistive technology product considering individual characteristics of each customer. Based on the scenario simulation, the objective is to detail the process and information flow, which are essential in bringing clients' specific needs into the design.
\end{abstract}

Keywords: Mass Customization; PLM; Additive Manufacturing. 


\section{Introduction}

Mass customization involves the manufacturing of customized products in high volumes. The customer is provided with individualized products and services produced through flexible processes [1]. According to Hayes and Wheelwright [2] a company that focuses on product development would choose a more flexible production process allowing the customer to take action in early stages of the product lifecycle. Lampel and Mintzberg [3] propose five types of strategy to deal with the decoupling point position - the moment in which the customer can interfere in the production process. Ranging from total interference to no interference at all on the part of the customer, the five types are: pure customization; tailored customization; customized standardization; segmented standardization; and pure standardization.

The costs associated with the anticipation of the decoupling point, from a sales interference point in direction to an interference in the design of the product, increases with the proximity to changes on the product structure and design [3]. Hence, pure customization and tailored customization have been difficult to implement. Considering these difficulties, an intermediary customized standardization strategy is followed by several companies that give the customer the ability to interfere in the assembly and distribution of the product. Dell, for example, allows its customers to configure their personal computers considering their specific needs and also to have it delivered according to their preferences. However, customers have restricted options defined as possible for assembly [4].

Silveira et al. [1] suggest that, conceptually, true mass customization products should be defined as those that possess all requirements made by individual customers. This implies the need of development in direction to tailored customization.

Zipkin [5] and Salvador et al. [4], consider that on a mass customization production system, each customer provides unique information so that the product can be tailored to his requirements, challenging the assumptions of traditional mass production. The increase in product variety, provided by the individualized products, would decrease internal operation performance considering the low flexibility of current manufacturing process and the high flexibility required by the production of individualized products [6].

ElMaraghy et al. [7] consider that the more flexible the manufacturing process is, the easier it is to change product design according to customers' individual needs. Maçanares et al. [8] comment that additive manufacturing (AM) technologies have been increasingly applied in a wide range of applications. Nowadays, AM technologies have been developed for new materials and are being used for new applications other than rapid prototyping in industries such as aerospace, automotive, and biomedical. In addition, Fogliatto et al. [9] state that the dissemination of AM will receive great attention in the near future, representing an auspicious research opportunity in the MC field.

This article presents a tailored customization strategy scenario that is enabled by information management, following PLM assumptions, and flexible manufacturing based on AM. The practical approach of this paper allows the information process mapping based on a real case scenario. The goal is to present the information flow that needs to be managed in a PLM context in order to enable a tailored customization strategy. The scenario considers a parametric product manufactured through AM. 
This paper is structured in five sections. Section 2 presents a literature review considering the main areas related to this project: MC, PLM, and AM. Section 3 discusses the employed methodology together with the proposed scenario. Section 4 presents the main results of the scenario development. Finally, section 5 discusses conclusions and future research efforts.

\section{Literature Review}

In this section, a literature review is presented considering the main areas for the development of the project. To that end, the concepts of MC are elucidated followed by PLM and AM.

\subsection{Mass Customization}

Pine II [10] and Davis [11] provide comprehensive definitions of MC. The authors consider that $\mathrm{MC}$ is the ability to provide to customers individually tailored products and services through agile, flexible, and integrated processes.

Pine II, in 1993, [10] portrayed that MC would be a new stage in industrial production. However, building a production system with the previously described characteristics is not a trivial task. To build a MC system, Zipkin [5] suggests three key capabilities be developed:

- Elicitation: communication platform from the customer to the company that aims to capture the information required to manufacture the customized good;

- Flexible process: the technology applied to manufacturing must be versatile and able to produce the individualized product with both agility and efficiency;

- Logistics: includes the process after the manufacturing and the distribution required keeping product identity and correctly delivering it to the customers.

For Fogliatto et al. [9], a MC process chain can be divided in four stages: elicitation, design, manufacturing, and supply chain. This paper scenario is focused on the three initial stages defined by Fogliatto et al. [9] - elicitation, design, and manufacturing.

Salvador et al. [4] discuss that, despite its difficulties, the MC concept is possible to be implemented in practice. Company executives tend to perceive $\mathrm{MC}$ as a fascinating but inapplicable idea. This kind of thought is due to the difficulties presented during the implementation of MC systems and the failure of high-level companies to implement it [4].

Once the client participates in configuring their product, the manufacturing, and production scheduling is going to be impacted. This situation requires a dynamic information exchange between areas of the company [12]. To overcome the challenges referring to information management, the use of PLM is proposed. 


\subsection{PLM}

Saaksvouri and Immonen [13] define PLM as a concept to managing process and control information during the entire product lifecycle. PLM solutions offer many features that support both the creation and the management of product data [14]. Portfolio management and capacity planning enable companies to react faster to market change. Management of dynamic requirements identify the impacts from changes over the product lifecycle phases [15].

To apply PLM concepts in a production environment, it is required to align people, processes, and resources with the PLM strategy. Besides, the use of Information Technology (IT) tools and systems to support information flow during product lifecycle is essential [15].

Ameri and Dutta [16] affirm that PLM is a collection of technologies and tools creating a shared platform to accelerate the information flow over the product lifecycle. Companies, however, not only use PLM solutions but also adopt other IT systems, devoted to different activities. Considering its central role, PLM uses the product as a central element, aggregating information from different areas and lifecycle phases [17].

PLM should collect the right amount of data throughout the product development process in order to avoid over-engineered solutions and to increase the flexibility of the products [18], as requested in MC.

\subsection{Additive Manufacturing}

Current technologies make online platforms available in which customers can express their preferences in an easy and low-cost way. 3D modeling systems are getting more accessible, and this allows customers to obtain a virtual preview of their products.

The advent of AM is changing the way of thinking in manufacturing. AM processes are flexible and can produce objects from different materials - plastic, ceramic, and metal. At first, AM was applied for prototyping only, but nowadays it can be applied to create a variety of final parts, including jewelry, tooling, and parts such as airplane engine components [8] [19].

AM built components by superposing several material layers until the final geometry [20] is obtained. There are different types of AM that use different kinds of technologies as, SLA (stereolithography), SLS (selective laser sintering), FDM (fused deposition modeling), etc. [8] [20].

FDM manufactures objects from a filament extruded through a nozzle and deposited on a platform. The nozzle works in a temperature that is higher than the material melting point. By going through the nozzle, the material is melted and, when in contact with the tray and the air, it loses heat and returns to the solid state. The nozzle moves in horizontal planes, parallel to the platform; the material is deposited in a thin layer, which, when superposed, form the object. [20]. 


\section{Methodology and Scenario}

The research methodology involves the deployment of a practical MC scenario based on PLM and AM, and the mapping of the process and the information flow considering a tailored customization strategy (Fig. 1).

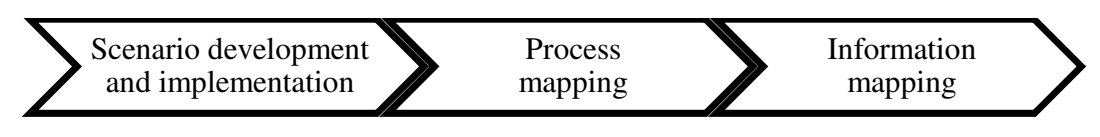

Fig. 1: Research methodology

The scenario presents a MC environment in which the client provides the information to be considered in his product, which is tailored according to his needs. The product chosen for this scenario is an assistive technology product. Assistive technology represents a major opportunity for customization. It is about individual demands related to people's specific characteristics, which vary from person to person. The product was designed considering the ideas that arose in the research center for development of accessible products during an event organized by the authors' research group.

The following requirements and constraints were considered for the product in this scenario:

1) Represents different types of customization:

a) Has components with variable dimensions [5];

b) Has more than two components [6].

2) Involves customization level capable of being managed through CAD and PLM:

c) Customization parameters as integer, real and string;

d) Parametric design.

3) Considers restrictions of AM machine available (a low-cost FDM machine):

e) Dimensions limited up to $320 \mathrm{~mm} \times 210 \mathrm{~mm}$ at the base and $160 \mathrm{~mm}$ height (3D Cloner ST. 2014);

f) Is composed only of plastic (PLA).

Considering the scenario requirements and the constraints, the product chosen was a forearm support to help people with superior limb disabilities to hold a cup. This product has two main functions:

1. Fixation at user's forearm;

2. Loading the cup.

In order to increase product variety, a modular architecture has been applied, with two main modules.

1. Forearm support module;

2. Cup support module. 
Fig. 2 presents a draft of the product structure showing the component arrangement and how it fits around the user's arm.

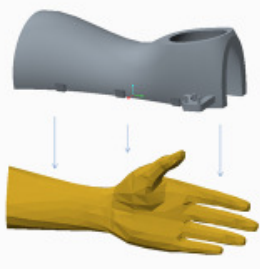

(1)

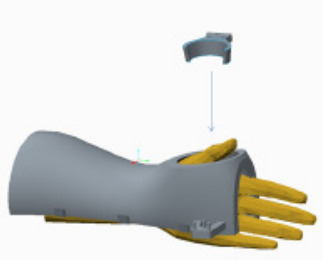

(2)

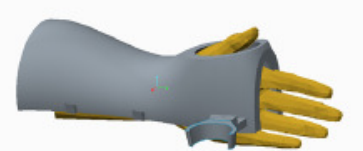

(3)

Fig. 2. Product architecture draft: (1) Forearm support - fits at user's forearm; (2) Elastics used below forearm support for fixation of the product on the user's forearm; (3) Cup support - fits over the forearm support

By simulating the scenario for different clients, it was possible to derive the MC process and observe the impacts on the information flow.

\section{Results}

This section presents the main research results considering the process mapping (section 4.1) and information mapping (section 4.2) of highly customizable products (tailored customization) with client-specific geometry based on PLM and AM.

\subsection{Process Mapping}

Considering the entire product lifecycle, there is a number of different systems involved in PLM. According to Schuh et al. [15], a comprehensive information management approach depends on the integration of multiple software systems, such as an Enterprise Resource Planning (ERP), Product Data Management (PDM) and a Computer Aided Design (CAD) [15]. Ameri and Dutta [16] consider that these systems should work with shared information across the entire product lifecycle.

In this context, the product structure definition and management has a core role in PLM [18], as it supports the creation of different variants of the product depending on users' requirements.

Following the MC process suggested by Fogliatto et al. [9], three stages of the product lifecycle were analyzed: design, elicitation, and manufacturing.

The design stage considered that the product has to be tailored to customers' necessities. The customizable part of the forearm support is the main structure that involves that customer's forearm. The gutter shape is molded by parameters seeking the fit around the clients' arm - according to their individual and specific needs. In order to parameterize the gutter, five cross sections were stablished on the forearm each corresponding to an ellipse (Fig. 3). Twenty-two parameters are necessary to determine the size and position of the ellipses. 

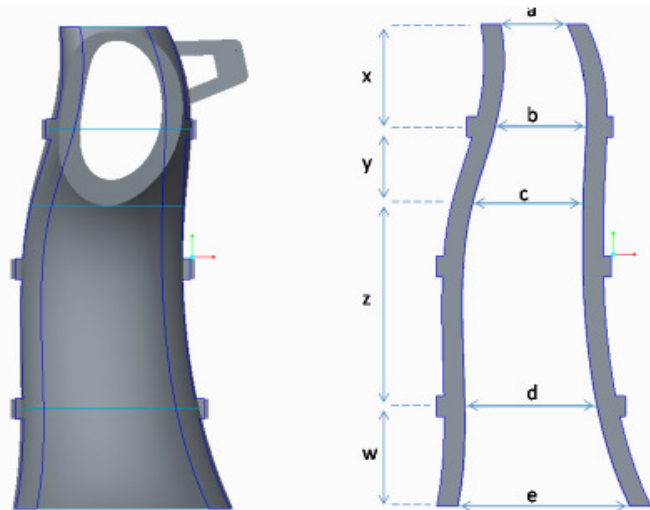

Fig. 3. Customizable sections of the forearm

Elicitation is the stage during which information on customers' necessities are collected and translated into data for the production system and to estimate the product quotation. A specific geometry variant of the product is generated for each customer as a response for his request for quotation. A unique identification number is generated and should continue to be managed in order to be traceable if the customer places an order.

In the manufacturing stage, the fabrication is started once the client order is placed. In this scenario, the manufacturing process is AM, in order to support client specific production of a plastic part with individualized geometry. A 3D model of the product variant is generated with clients' individual characteristics.

In order to manufacture the customized 3D model in the scenario, the CAD file is saved as an STL file; this file is then processed in a machine specific software in order to generate a Gcode file, which contains the machining codes; the Gcode file is sent to the machine, in which the 3D model is produced out in PLA, completing the scenario, as shown in Fig. 4

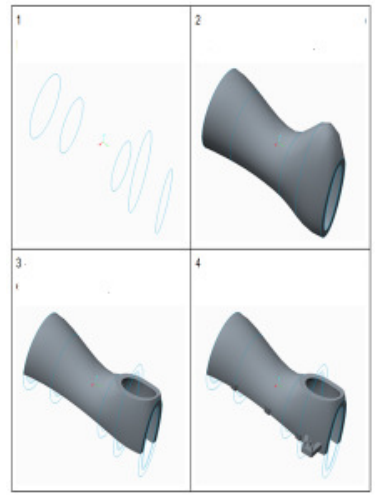

(1)

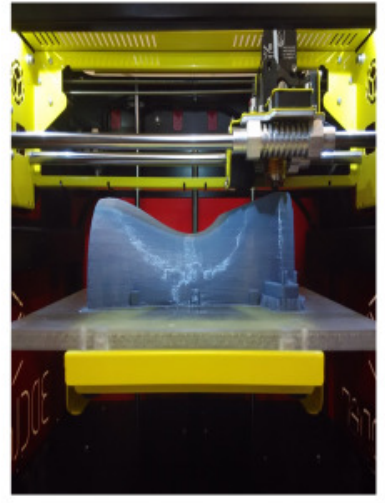

(2)

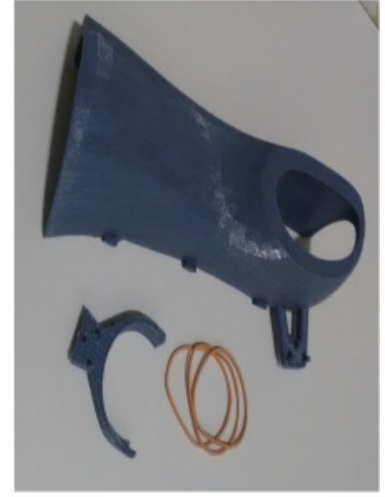

(3)

Fig. 4. Manufacturing steps: (1) Variant modeling. (2) 3D printing. (3) Variant ready to use 
Once the process is mapped, it is essential to map the information that is being generated and exchanged during the scenario. This analysis is presented in section 4.2.

\subsection{Information Mapping}

Each lifecycle phase embraces the accomplishment of several activities. The realization of each activity takes place in different places and generates information. Table 1 relates the lifecycle stage with the information it provides and the kind of documents it generates. This table is constructed considering the information collected during the scenario analysis.

Table 1. Information Mapping.

\begin{tabular}{ll}
\hline Stage & Information \\
\hline $\begin{array}{l}\text { Product architecture } \\
\text { definition }\end{array}$ & $\begin{array}{l}\text { Describes general functionalities of the product. Describes the } \\
\text { components and the relations between them. }\end{array}$ \\
$\begin{array}{l}\text { Component parametric } \\
\text { modeling }\end{array}$ & $\begin{array}{l}\text { 3D model of the product and its parts. Embrace every possible } \\
\text { variation that the part can possess. }\end{array}$ \\
Assembly modeling & $\begin{array}{l}\text { Brings assembly logic and must withstand all variations that the } \\
\text { customized product can have. }\end{array}$ \\
$\begin{array}{l}\text { Customer request for } \\
\text { quotation }\end{array}$ & $\begin{array}{l}\text { Customers' individual information including parameters values to } \\
\text { determine the product-specific configuration. Has ID information to } \\
\text { allow product tracking. }\end{array}$ \\
Variant definition & $\begin{array}{l}\text { 3D model of a specific product to a specific customer. Display the } \\
\text { individual characteristics requested by the client. }\end{array}$
\end{tabular}

Manufacturing instructions and machine language definition

Manufacturing information estimation

Quotation

Purchase order

Manufacturing order
File in machine language containing command lines to manufacture product variant.

Machine time, quantity of raw material, and estimated manufacturing costs, generated by G-code simulation.

Document presented to the client with requested information, including price.

Document that formalizes the purchase order by the client

Manufacturing order sent to the factory environment with the characteristics requested by the client. 
Product related information listed in Table 1 is managed by PLM [15]. Considering the reference model suggested by Zancul [14], the information listed in Table 1 requires PLM functionalities such as: product structure, product planning, product costs analysis, production process planning, document management, and configuration management. These functions are applied to manage the information that is provided along the entire lifecycle.

\section{Conclusions and Discussion}

Tailored customization strategies have been difficult to implement in real cases in the industry. Changing the decoupling point of a product to a tailored strategy requires more flexible production processes and structured information flow. To overcome this situation, PLM and AM are being considered in this scenario for manufacturing personalized assistive technology products based on 3D parametric models. Integrating lifecycle phase with customers' needs and information together with the manufacturing process is the key in building MC environments.

This paper presents the information and the process flow of a tailored customization strategy based on data collected during the development of the research scenario. The mapped process and information can be used to reproduce $\mathrm{MC}$ scenarios dealing with customers' integration to the process and the information flow.

For future research, many questions that to this date have not been fully explored remain open. It is recommended to understand what is the best way to collect client information during the elicitation stage; how to integrate the information generated in a PLM environment; and the extension of the concepts to the last stage of the MC, as proposed by Fogliatto et al. [9] - the supply chain.

\section{Acknowledgment}

The authors thank the São Paulo Research Foundation (FAPESP) and the Brazilian National Council for Scientific and Technological Development (CNPq) for supporting the research.

\section{References}

1. G. Da Silveira, D. Borenstein, and H. S. Fogliatto, "Mass customization : Literature review and research directions," Int. J. Prod. Econ., vol. 72, no. 49, pp. 1-13, 2001.

2. R. Hayes and S. Wheelwright, "Link manufacturing process and product life cycles," Harv. Bus. Rev., no. January, 1979.

3. J. Lampel and H. Mintzberg, "Customizing Customization.," Sloan Manage. Rev., vol. 38, pp. 21-30, 1996.

4. F. Salvador, P. M. De Holan, and F. Piller, "Cracking the Code of Mass Customization I MIT Sloan Management Review," MIT Sloan Manag. Rev., no. 50315, 2009. 
5. P. Zipkin, "The Limits of Mass Customization.," MIT Sloan Manag. Rev., vol. 42, pp. 1-7, 2001.

6. F. Salvador, C. Forza, and M. Rungtusanatham, "Modularity, product variety, production volume, and component sourcing: Theorizing beyond generic prescriptions," J. Oper. Manag., vol. 20, pp. 549-575, 2002.

7. H. ElMaraghy, G. Schuh, W. Elmaraghy, F. Piller, P. Schönsleben, M. Tseng, and a. Bernard, "Product variety management," CIRP Ann. - Manuf. Technol., vol. 62, pp. 629652, 2013.

8. C. G. Mançanares, E. de S. Zancul, J. Cavalcante da Silva, and P. a. Cauchick Miguel, "Additive manufacturing process selection based on parts' selection criteria," Int. J. Adv. Manuf. Technol., 2015.

9. F. S. Fogliatto, G. J. C. Da Silveira, and D. Borenstein, "The mass customization decade: An updated review of the literature," Int. J. Prod. Econ., vol. 138, no. 1, pp. 14-25, 2012.

10. B. J. Pine II, "Mass customizing products and services," Strateg. Leadersh., vol. 21, pp. 655, 1993.

11. S. Davis, "From future perfect: mass customizing," Plan. Rev., pp. p. 16-21, 1989.

12. J. Jiao, M. Tseng, Q. Ma, and Y. Zou, "Generic Bill-of-Materials-and-Operations for HighVariety Production Management," Curr. Eng., vol. 8, pp. 291-322, 2000.

13. A. . Saaksvuori and A. Immonen, Product lifecycle management. Berlin, 2004.

14. E. Zancul, "PLM reference model: a preliminary proposal for reference model evolution," in PLM Conference, 2012.

15. G. Schuh, H. Rozenfeld, D. Assmus, and E. Zancul, "Process oriented framework to support PLM implementation," Comput. Ind., vol. 59, pp. 210-218, 2008.

16. F. Ameri and D. Dutta, "Product Lifecycle Management: Closing The Knowledge Loops," Comput. Des., pp. 577-590, 2005.

17. E. Zancul, L. Piccini, S. Berglenher, and L. Lachenmaier, "Product Lifecycle Management functional reference model for software support.," in Verlag Berlin Heidelberg, Springer, Ed. 2013.

18. G. Schuh, D. Assmus, and E. Zancul, "Product Structuring - the Core Discipline of Product Lifecycle Management," in 13th CIRP International Conference on Life Cycle Engineering, 2006.

19. A. Gandhi, C. Magar, and R. Roberts, "How technology can drive the next wave of mass customization," MC Kinsey Company's Bus. Technol. J., pp. 1 - 8, 2014.

20. S. Upcraft and R. Fletcher, "The rapid prototyping technologies," Assem. Autom., vol. 23, pp. 318-330, 2003. 